\title{
The effects of stemflow on redistributing precipitation and infiltration around shrubs
}

\author{
Shengqi Jian ${ }^{1}$, Xueli Zhang ${ }^{2}$, Dong $\mathrm{Li}^{1}$, Deng Wang ${ }^{1}$, Zening $\mathrm{Wu}^{1}$, Caihong $\mathrm{Hu}^{1 *}$ \\ ${ }^{1}$ College of Water Conservancy \& Environment, Zhengzhou University, Science road 100, Zhengzhou, China. \\ ${ }^{2}$ Zhongyuan District Environmental Protection Bureau, Zhengzhou City, Gangpo road 4, Zhengzhou, China. \\ * Corresponding author. Tel.: +86 18603814081. E-mail: jiansq@zzu.edu.cn
}

\begin{abstract}
The experiments of stemflow of two semiarid shrubs (Caragana korshinskii and Hippophae rhamnoides) and its effect on soil water enhancement were conducted from $1^{\text {st }}$ May to $30^{\text {th }}$ September of 2009-2013 in the Chinese Loess Plateau. Stemflow values in $C$. korshinskii and $H$. rhamnoides averaged $6.7 \%$ and $2.4 \%$ of total rainfall. The rainfall threshold for stemflow generation was 0.5 and $2.5 \mathrm{~mm}$ for $C$. korshinskii and $H$. rhamnoides. When rainfall was less than $17.0 \mathrm{~mm}$, the funnelling ratios were highly variable, however, stable funnelling ratios were found for rainfall greater than $17.0 \mathrm{~mm}$ for $C$. korshinskii. The funnelling ratios of $H$. rhamnoides first increased until a threshold value of $10.0 \mathrm{~mm}$ and then the funnelling ratios begin stabilize. The wetting front depths in the area around stem was 1.4-6.7 and 1.3-2.9 times deeper than area outside the canopy for C. korshinskii and H. rhamnoides. Soil moisture at soil depth 0-200 cm was $25.6 \%$ and $23.4 \%$ higher in soil around stem than that outside canopy for C. korshinskii and H. rhamnoides. The wetting front advanced to depths of 120 and $100 \mathrm{~cm}$ in the area around stem and to depths of $50 \mathrm{~cm}$ in the area outside the canopy for $C$. korshinskii and $H$. rhamnoides suggested that more rain water can be conserved into the deep soil layers through shrub stemflow. Soil moisture was enhanced in the area outside the shrub canopy, only when rainfall depth is $>$ 4.7 and $5.1 \mathrm{~mm}$, which is an effective rainfall for the area for $C$. korshinskii and H. rhamnoides. While for the area around stem of $C$. korshinskii and H. rhamnoides, the corresponding threshold values are 3.2 and $4.3 \mathrm{~mm}$. These results confirmed that stemflow has a positive effect on soil moisture balance of the root zone and the enhancement in soil moisture of deeper soil layers.
\end{abstract}

Keywords: Stemflow; Wetting front; C. korshinskii; H. rhamnoides; Loess Plateau; China.

\section{INTRODUCTION}

Vegetation growth and ecosystem processes are typically limited by water availability in semi-arid ecosystems (Kéfi et al., 2007; Noy-Meir, 1973). Revegetation experiments have been established for more than 50 years in Loess Plateau, northwestern China, using mainly xerophytic shrubs such as Caragana korshinskii, and Hippophae rhamnoides, which are considered as a successful model for soil and water conservation and ecological restoration. Since rainfall is often the sole source of water replenishment in semiarid area, the availability of water for vegetation growth and survival is critical to the development of this rainfed revegetated ecosystem ( $\mathrm{Li}$ et al., 2008; Wang et al., 2005) and merits great attention in the research of ecological restoration.

Understory rainfall within forested environments comprises throughfall, which reaches forest floors by passing directly through or dripping from tree canopies, and stemflow, which reaches forest floors after the incident rainfall is intercepted by leaves and branches and subsequently diverted to the boles of trees. Throughfall is usually the major understory rainfall flux with growing-season values often representing $>70 \%$ of the incident rainfall. Levia and Germer (2015) found that stemflow values accounted for $3.5 \%, 11.3 \%$ and $19.0 \%$ of rainfall for tropical, temperate and semiarid regions, respectively.

Although stemflow may be volumetrically minor compared to throughfall at the stand scale, stemflow has been shown to be an important point-scale water flux. Stemflow is the process that directs precipitation down plant branches and stems. The redirection of water by this process is of ecohydrological and biogeochemical importance in forested and agricultural ecosystems because it is a spatially localized point input of water and nutrients at the plant stem (Levia and Frost, 2003; Moran et al., 2009; Voigt, 1960). Stemflow has a significant influence on runoff generation, soil erosion, groundwater recharge, spatial patterning of soil moisture, soil solution chemistry and the distribution of understory vegetation and epiphytes (Levia and Frost, 2003). However, stemflow is almost always considered as a minor component of forest canopy water budgets as compared to interception and throughfall, and therefore it receives minor attention and is under-represented in the literature (Llorens and Domingo, 2007). Most previous studies about stemflow have been conducted in tropical and temperate forests primarily (Levia and Germer, 2015; Tang, 1992; Wang et al., 2013); by contrast, relatively few studies on the characteristics of stemflow were documented for shrub vegetation in semiarid and arid regions (Carlyle-Moses, 2004), and almost no longterm experiments were conducted (more than 5 years).

Stemflow can be an important source to replenish soil moisture in arid and semiarid lands where water resources are limited (Tromble, 1987; Wang et al., 2011a). Wang et al. (2011a) found that stemflow water of $C$. korshinskii can reach a soil depth of $90 \mathrm{~cm}$ in Tengger Desert, it is favourable for the infiltrated water redistribution in the deeper soil profile of the root zone. Also, Zhang et al. (2013) agreed to the findings, he thought infiltration of stemflow alongside stems into deep soil profiles, creating islands of soil moisture, can be an important potential source of soil moisture allowing shrubs to remain physiologically active during drought spells. Návar and Bryan (1990) found that stemflow transported into the soil area close to the shrub stems showed a water input that was five times higher than by other areas beneath the shrub canopies in northeastern Mexico. Mauchamp and Janeau (1993) calculated that Flourensia cernua can channel approximately $50.0 \%$ of the 
incident gross precipitation to the base of plant stems. Nulsen et al. (1986) reported that the infiltration depth of stemflow in mallee is as great as $28 \mathrm{~m}$, and that this input water is possibly consumed in the dry period (Martinez-Meza and Whitford, 1996). In addition, other semiarid shrubs are also adapted to divert rainfall to their stems base as stemflow where it subsequently infiltrates the soil and remains available for plant uptake at deeper soil layers (Jiao et al., 2011; Li et al., 2008; Martinez-Meza and Whitford, 1996).

C. korshinskii and $H$. rhamnoides are the dominant woody species in the Loess Plateau. They are widely used for ecological restoration (Wei et al., 2007; Zhang et al., 2009). The effects of both rainfall and soil surface characteristics on soil water replenishment in re-vegetated ecosystems have been studied (Wang et al., 2011b; Wang et al., 2013; Zhang et al., 2013). However, the previous studies were mainly based on one year experiment data, the results obtained had occasionality. Thus, the current study prolonged the time of experiment $(5$ years) to improve the credibility of the results. Also, the effect of stemflow on infiltration patterns associated with the soil moisture replenishment is almost totally unexplored.

The aims of the study were to (1) determine the influence of rainfall on stemflow production and funnelling ratios of $C$. korshinskii and $H$. rhamnoides in a long-term observation; (2) understand the effect of stemflow on soil moisture in the Loess Plateau, China; (3) evaluate the infiltration process of stemflow water in the semiarid shrubs of vegetation restoration in the Loess Plateau, China.

\section{MATERIALS AND METHODS Study site}

The experiments were conducted in C. korshinskii and $H$. rhamnoides plantations from 1st May to 30th September of $2009-2013$ in the Anjiapo catchment, Dingxi County $\left(35^{\circ} 35^{\prime} \mathrm{N}\right.$, $\left.104^{\circ} 39^{\prime} \mathrm{E}\right)$ of Gansu province in western Chinese Loess Plateau. The annual mean precipitation is $420.0 \mathrm{~mm}$ with great seasonal variations. Over $60.0 \%$ of the precipitation falls between July and September and over $50.0 \%$ occurs in the form of storms. The average monthly air temperature ranges from -7.4 to $27.5^{\circ} \mathrm{C}$, with mean annual temperature of $6.3^{\circ} \mathrm{C}$. Average annual pan evaporation is $1510.0 \mathrm{~mm}$. The range of altitude above sea level is from $1850 \mathrm{~m}$ to $2000 \mathrm{~m}$. The soil belongs to Chernozem according to IUSS Working Group WRB (2006). It is developed on loess parent material has a relatively thick profile (Wang et al., 2010). The land uses in the study area include croplands, grasslands, artificial shrublands, and woodlands.

Vegetation restoration has been widely implemented in the area where $C$. korshinskii and $H$. rhamnoides were planted at $3 \times 3 \mathrm{~m}$ spacing. C. korshinkii is nitrogen fixating leguminous shrub with even pinnate compound leaves and numerous slender branches, plant surface is smooth. Each specimen occupies the shape of a semi-sphere. Each pinna has 5-8 pairs of leaflets, which are ovate in shape with $7-8 \mathrm{~mm}$ in length and 2-5 $\mathrm{mm}$ in width. H. rhamnoides is non-leguminous shrub, the bulk of the plant is shaped like a cone with a main stem and narrow but thick leaves (length, 30-60 mm; width, 5-10 mm), and has rough bark. C. korshinskii had more developed root systems than $H$. rhamnoides, and more than $50.0 \%$ of fine root length was concentrated at depths between 0 and $40 \mathrm{~cm}$ for $C$. korshinskii and H. rhamnoides (Jian et al., 2014a). The sparse grasses were observed beneath the shrub canopies in $C$. korshinskii and H. rhamnoides plantation. Fig. 1 displays the general view the two shrub species and their leaf characteristics.

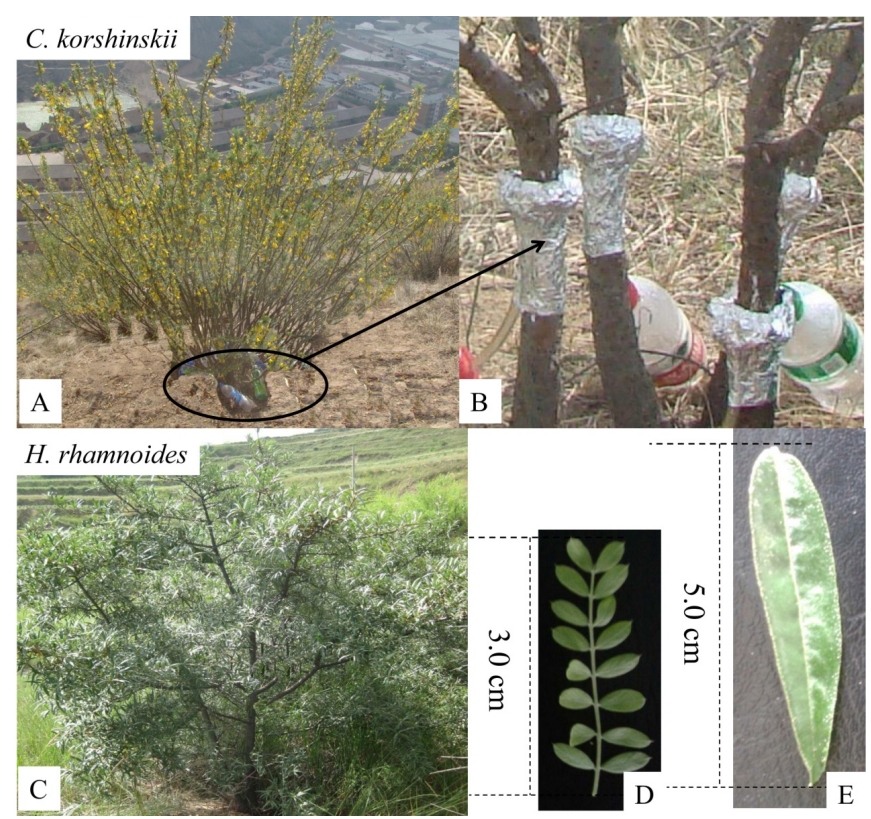

Fig. 1. Photographs showing C. korshinskii (A) and H. rhamnoides (C), the stemflow collection systems (B) and their leaf characteristics (D, C. korshinskii; E, H. rhamnoides).

\section{Experimental design}

Stemflow was measured for 10 fully mature C. korshinskii individuals and 10 fully mature $H$. rhamnoides individuals of 32 years old that were planted in 1989 as 2-year-old seedlings, which were located in flat terrain (we presumed that all of the stemflow infiltrated the soil beneath the shrubs), and they were exposed to sun and wind. The number, length, height and diameter of the branches were measured. The branch angle was calculated by the branch height from the ground surface to the tip of the branch vertically and the distance of the branch away from the stem horizontally. The shrub canopy projected area was calculated by taking the longest and shortest diameters through the centre of the fullest part of the canopy. Canopy bulk volume was calculated with the formula of an inverted cone (Table 1). The selected branch surface was burnished by fine sandpaper about $10 \mathrm{~cm}$ above the ground. Then, stemflow was collected using collars constructed from flexible aluminum foil plates that were fitted around the entire circumference of the branches. Each collar was sealed to the branch using all weather silicon caulking. The aluminium plate stemflow collectors extend less than $0.5 \mathrm{~cm}$ from the stem to prevent catching throughfall water as stemflow. Stemflow was caught from the collar to a collection container through a plastic hose (Fig. 1). By dividing stemflow volume of each shrub by its canopy projected area, we got the stemflow depth. Rainfall amount and intensity were measured with a standard rain gauge and a siphon-type recording rain gauge (model TE525, metric; Texas Electronics, Dallas, TX). An individual rainfall event was defined as a rainfall separated by a dry period of at least $6 \mathrm{~h}$ according to Dunkerley (2008).

Herwitz (1986) suggested that the quantitative importance of stemflow at the point scale can be expressed as a funnelling ratio, $F$ :

$F=V /(B \times P)$

where, $V$ is the stemflow volume (1), $B$ is basal area of the tree $\left(\mathrm{m}^{2}\right)$, and $P$ is the incident rainfall at the top of the canopy $(\mathrm{mm})$. 
The effects of stemflow on redistributing precipitation and infiltration around shrubs

Table 1. Descriptive statistics (mean \pm standard deviation) of branches and canopy projection of the 10 sampled C. korshinskii individuals and $10 \mathrm{H}$. rhamnoides individuals used in the experiments.

\begin{tabular}{lllllll}
\hline \multicolumn{7}{c}{ Shrub branch } \\
\hline Species & Number & Diameter $(\mathrm{cm})$ & Length $(\mathrm{cm})$ & Height $(\mathrm{cm})$ & Angle $\left({ }^{\circ}\right)^{\mathrm{a}}$ & ${\text { Projected area }\left(\mathrm{m}^{2}\right)}{\text { Canopy bulk }\left(\mathrm{m}^{3}\right)}^{3}$ \\
\hline C. korshinskii & $19 \pm 6$ & $1.56 \pm 0.22$ & $194 \pm 22$ & $170 \pm 11$ & $55 \pm 9$ & $5.01 \pm 1.10$ \\
H. rhamnoides & $11 \pm 3$ & $1.69 \pm 0.34$ & $206 \pm 27$ & $191 \pm 17$ & $59 \pm 11$ & $4.24 \pm 1.47$ \\
\hline
\end{tabular}

${ }^{a}$ Angle in degree of the upward branch to the ground surface.
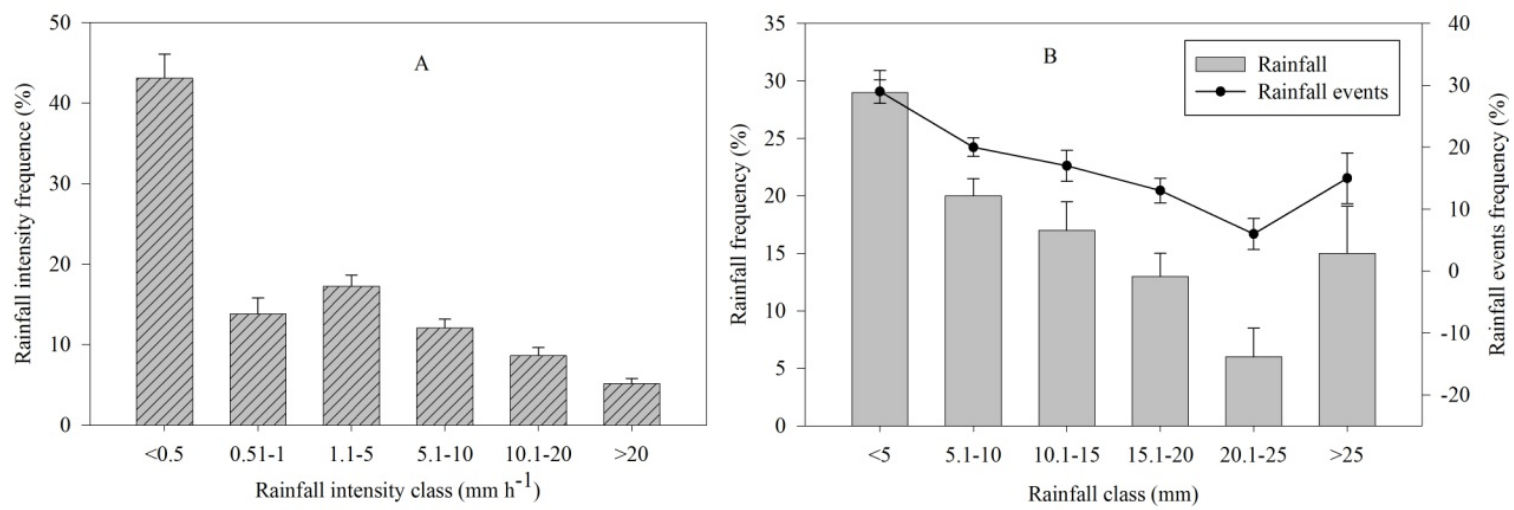

Fig. 2. The frequency distributions on the rainfall intensity, rainfall and rainfall events from $1^{\text {st }}$ May to $30^{\text {th }}$ September of $2009-2013$.

The product $B \times P$ provides the volume of water that would have been caught by a rain gauge having an opening equal to that of the tree $B$. Thus, $F$ represents the ratio of the amount of precipitation delivered to the base of the tree to the rainfall that would have reached the ground if the tree were not present. Funnelling ratios $>1$ indicate that canopy components other than the tree bole are contributing to stemflow (Carlyle-Moses and Price, 2006; Herwitz, 1986).

Another two shrub individuals for each species were selected to assess the influence on stemflow in soil moisture and the advancement patterning of stemflow in the soil, which were located in flat terrain to make sure no stemflow water and throughfall water to run off along the soil surface, and all of the stemflow infiltrated the soil beneath the shrubs. Volumetric soil moisture was measured by means of probes (Em 50, Decagon Devices, Pullman, WA, USA), installed at twenty depths in the area around the shrub stem and at about $30 \mathrm{~cm}$ from the plant periphery in the bare area $(5,10,15,20,25,30,35,40,45,50$, $60,70,80,90,100,120,140,160,180$, and $200 \mathrm{~cm})$. The probe has three rods with $5.5 \mathrm{~cm}$ length interval at $1.5 \mathrm{~cm}$. For probe installation, two same trenches were dug into the soil (around the shrub stem and at about $30 \mathrm{~cm}$ from the plant periphery in the bare area) with a sufficient width, the probes can be inserted. The probes were inserted into the soil through the undisturbed side of the trench and placed horizontally in the direction of the shrub site. The trenches were carefully refilled after the probes installation was completed, avoiding disturbance as far as possible, and the surface was contoured similar to the surrounding area. We installed the probes in April of 2008, the stabilization time is more than one year. We collected the data of wetting front depths within 24 hours after each rainfall event. Also, soil water content was measured every 30 days by means of oven-drying to validate the soil moisture data provided by the probes during the study period. Soil bulk density was measured at each soil layer where the soil moisture probes were installed by cutting ring method, the averaged soil bulk density is $1.24 \mathrm{~g} \mathrm{~cm}^{-3}$ and $1.31 \mathrm{~g} \mathrm{~cm}^{-3}$ for beneath the shrub canopies and in the interspaces, respectively (Jian et al., 2014a). In the current study, we ignored the water intercepted by organic litter of leaves and other materials beneath the shrub canopies, this is because of there were few organic litter of leaves and sparse grasses were observed beneath the shrub canopies. Also, in our previous study (Jian et al., 2014b), we found that there were small differences in soil evaporation between the area around the shrub stem and outside the shrub canopy, and this is due to the sparse vegetation (at $3 \mathrm{~m} \times 3 \mathrm{~m}$ spacing), thus we ignored the influence of shading beneath shrubs to soil moisture.

\section{Data analysis}

Descriptive statistics were compiled for rainfall characteristics (depth and intensity), stemflow mounts, funnelling ratios and soil moisture. Data on soil moistures of these five types were analyzed using SPSS for Windows 18.0. A one-way ANOVA was performed to test the effects of the different locations (area around the stem and area outside the canopy for $C$. korshinskii and $H$. rhamnoides) on soil moisture. Stepwise multiple linear regressions (the type is backward elimination) (SPSS v18.0 for Windows) were used to analyze the relationship between stemflow and the canopy structures (height, projected area, canopy bulk, branch length, diameter and angle).

The multicollinearity was addressed. The soil moisture was measured with a probe matching the different depths of the soil profiles. Based on the principle of soil water balance, the cumulative infiltration can therefore be described as:

$$
I=\left(S_{e}-S_{b}\right) \times Z_{f}
$$

where $S_{e}$ is the soil moisture (\%) at the end stage, $S_{b}$ is the soil moisture (\%) in the beginning, $Z_{f}$ is the infiltration depth $(\mathrm{cm})$, and $I$ is the cumulative infiltration $(\mathrm{mm})$.

\section{RESULTS AND DISCUSSION Rainfall characteristics}

There were 236 rainfall events during the experimental period (from $1^{\text {st }}$ May to $30^{\text {th }}$ September of 2009-2013). There were 75 rainfall events occurred during the day and 161 rainfall events occurred at night. The plants were not completely dry before 37 rainfall events. The results indicated that small rainfall intensity $\left(<0.5 \mathrm{~mm} \mathrm{~h}^{-1}\right)$ accounted for $43.9 \%$ of rainfall events (Fig. 2A). The annual rainfall averaged $363.2 \mathrm{~mm}$, and 
the distribution of rainfall was presented in Fig. 2B. Stemflow was measurable for 151 rainfall events during the experimental period.

\section{Stemflow characteristics}

The stemflow was strongly related to rainfall. The stemflow increased with increasing rainfall depth and there was a significantly positive linear relationship between them (Fig. 3). The rainfall threshold for stemflow generation was 0.5 and $2.5 \mathrm{~mm}$ for $C$. korshinskii and $H$. rhamnoides according to the linear regression equations (Diskin, 1970). The correlations between stemflow and mean rainfall intensity and maximum rainfall intensity in 10 minutes were weak (Data not shown). Stemflow values averaged $6.7 \%$ and $2.4 \%$ of total rainfall with a range of $1.6-17.8 \%$ and $0.06-4.6 \%$ for $C$. korshinskii and $H$. rhamnoides (Fig. 4).

Stepwise multiple linear regression equation of stemflow with the canopy structures (height, projected area, canopy bulk, branch length, diameter and angle) set out in Eq. (3) and (4) for C. korshinskii and H. rhamnoides (Aboal et al., 1999). The equation contained two independent variables indicated that stemflow increase with the increases in the projected area and branch angle.

$$
\begin{array}{ll}
S F_{\text {C.korshinskii }}=0.24 X_{1}+0.53 X_{2}+32.25, & R^{2}=0.88, F=26.47, \\
& P<0.001 \\
S F_{H . \text { rhamnoides }}=0.16 X_{1}+0.46 X_{2}+27.13 & R^{2}=0.79, F=20.00, \\
& P<0.001
\end{array}
$$

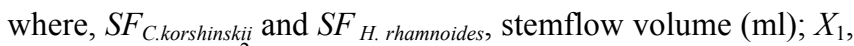
Projected area $\left(\mathrm{m}^{2}\right) ; X_{2}$, branch angle $\left(^{\circ}\right)$.

Multiple linear regression equations of stemflow with the rainfall depth, mean rainfall intensity and maximum rain intensity in 10 minutes $\left(I_{10}\right)$ were presented in Table 2 suggested that stemflow increased as $12.6-18.0 \%$ and $0.7-5.9 \%$ with

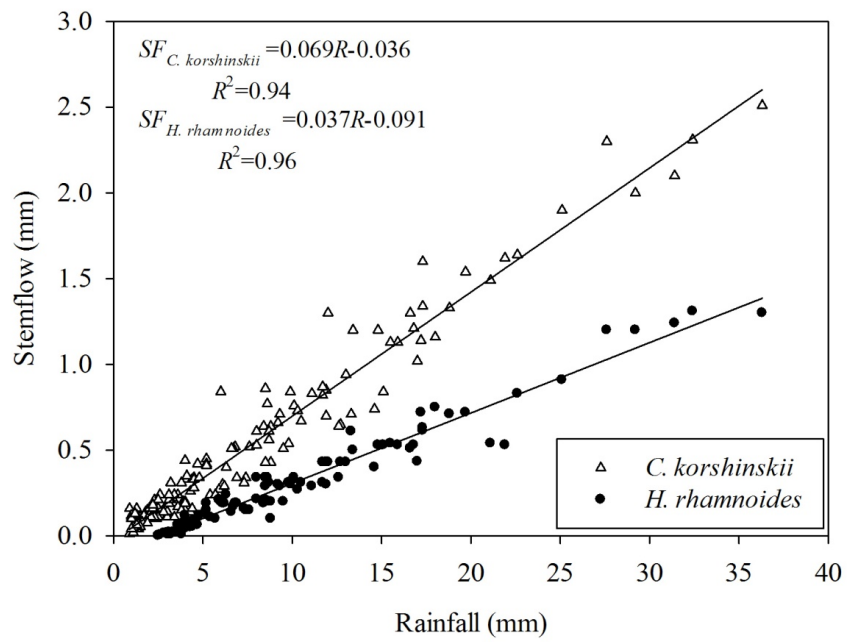

Fig. 3. Relationship between rainfall and individual stemflow from May to September of 2009-2013 for C. korshinskii and H. rhamnoides. increasing the rainfall and $I_{10}$, respectively, but as $1.1-2.6 \%$ with the decrease in the mean rainfall intensity, indicating that stemflow was more governed by the rainfall depth than the mean rainfall intensity and $I_{10}$ for $C$. korshinskii and $H$. rhamnoides.

\section{Funnelling ratios}

When rainfall was less than $17.0 \mathrm{~mm}$, the funnelling ratios were highly variable, however, the stable funnelling ratios were found when rainfall was greater than $17.0 \mathrm{~mm}$ for C. korshinskii (Fig. 5). The funnelling ratios of H. rhamnoides first increased until a threshold value of $10.0 \mathrm{~mm}$ and then the funnelling ratios began to be stable. The mean funnelling ratio was 167.4 and 59.1, and ranging from 38.9 to $444.4,1.5$ to 114.7 for C. korshinskii and H. rhamnoides.

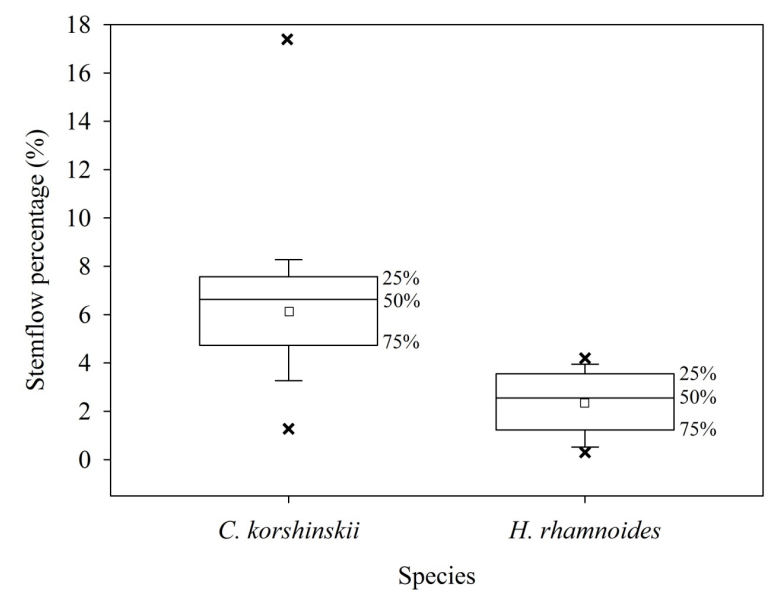

Fig. 4. Box-and-whisker diagrams showing median, 25, 50 and 75 percentiles and standard deviation for individual stemflow percentage from May to September of 2009-2013 for C. korshinskii and H. rhamnoides. ( $\square)$ represents mean value, $(\times)$ maximum and minimum value.

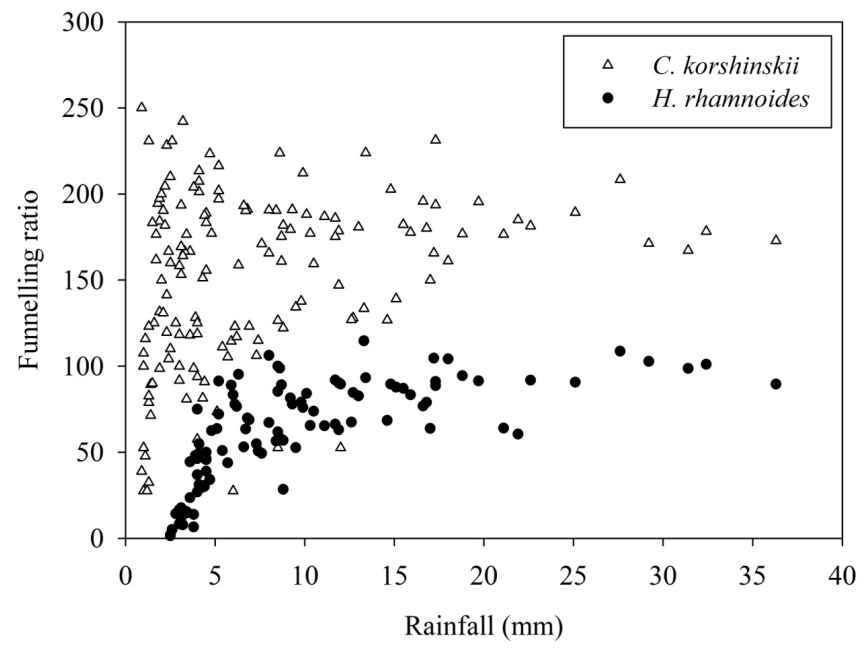

Fig. 5. Relationship between funneling ratio and daily rainfall from May to September of 2009-2013 for C. korshinskii and H. rhamnoides.

Table 2. Regression equations and coefficient values between stemflow and rainfall depth, mean rainfall intensity and maximum rain intensity in 10 minutes.

\begin{tabular}{lcccc}
\hline Shrubs & Equation & $r$ & $F$ value & Sig. level \\
\hline C. korshinskii & $S F=-0.16+0.18 P-0.026 I+0.059 I_{10}$ & 0.831 & 40.56 & $<0.0001$ \\
H. rhamnoides & $S F=-0.14+0.13 P-0.011 I+0.007 I_{10}$ & 0.724 & 31.29 & $<0.0001$ \\
\hline
\end{tabular}

$* S F$, stemflow $(\mathrm{mm}) ; P$, rainfall depth $(\mathrm{mm}) ; I$, rainfall intensity $\left(\mathrm{mm} \mathrm{h}^{-1}\right) ; I_{10}$, maximum rain intensity in 10 minutes; $r$, correlation coefficient. 


\section{Soil water status}

Stemflow water can be transported into deeper soil layers around shrub stem than that outside the shrub canopy, producing more infiltration of water in the root zone. The wetting front depths increased with increasing rainfall depths and followed significant logarithmic equations for $C$. korshinskii and $H$. rhamnoides (Fig. 6). The wetting front depths in the area around stem were 1.4-6.7 and 1.3-2.9 times deeper than that outside the canopy for $C$. korshinskii and H. rhamnoides (rainfall depths were ranging from 1.1 to $36.3 \mathrm{~mm}$ ). Soil moisture at soil depth $0-200 \mathrm{~cm}$ was $25.6 \%$ and $23.4 \%$ higher in area around stem than that away from the shrubs for C. korshinskii and $H$. rhamnoides from May to September of 2012. During the experimental period (from May to September of 2009-2013), the soil moisture in the other four years $(2009,2010,2011$ and 2013) had the similar trend with the year of 2012 (Data not shown) (Fig. 7).

\section{Advance of the wetting front}

The heaviest rainfall event, it occurred on $12^{\text {th }}$ August, which was used to analyze the advance of the wetting front (Fig. 8A). In the area around the stem of C. korshinskii, after rainfall lasted for $140 \mathrm{~min}$, the wetting front reached $5 \mathrm{~cm}$. The soil moisture increased rapidly. The wetting front took about 60 min from $5 \mathrm{~cm}$ to $10 \mathrm{~cm}, 10 \mathrm{~cm}$ to $15 \mathrm{~cm}$ and $15 \mathrm{~cm}$ to $20 \mathrm{~cm}$, and reached the constant values of $27.4 \%, 23.2 \%$ and $20.5 \%$, respectively. After approximately $130 \mathrm{~min}$ of slow increase, the soil moisture became stable at $14.0 \%$ in a depth of $25 \mathrm{~cm}$. The wetting front reached a depth of $30 \mathrm{~cm}$ after $12 \mathrm{~h}$. The soil moisture reached approximately $12.1 \%$ at a depth of $50 \mathrm{~cm}$ after a period of slow increase. The wetting front of this position was as depth as $120 \mathrm{~cm}$ approximately 7 days later (Fig. 8B).

In the area outside the canopy of $C$. korshinskii, the wetting front reached a depth of $5 \mathrm{~cm}$ approximately $90 \mathrm{~min}$ earlier than that around the stem of $C$. korshinskii, but took longer time to achieve the second stable level $(10 \mathrm{~cm})$, at $25.6 \%$ after the initial $10.8 \%$. At this position, the wetting front took approximately $13 \mathrm{~h}$ to reach the depths of $15 \mathrm{~cm}$. The water infiltrated to a depth of $50 \mathrm{~cm}$ ultimately (Fig. 8C).

The wetting front reached a depth of $5 \mathrm{~cm}$ approximately 60 min later in the area around the stem of $H$. rhamnoides than that around the stem of $C$. korshinskii. After approximately $220 \mathrm{~min}$ of rapid increase, the soil moisture remained at a constant value of $23.0 \%$ in a depth of $10 \mathrm{~cm}$. At this position, the wetting front took approximately 7 and $9 \mathrm{~h}$ to reach the depths of $15 \mathrm{~cm}$ and 20 $\mathrm{cm}$. The water finally infiltrated to a depth of $100 \mathrm{~cm}$ (Fig. 8D).

The area outside the canopy of $H$. rhamnoides had the lowest initial soil moisture. The wetting front took $70 \mathrm{~min}$ from the beginning of precipitation to reach a depth of $5 \mathrm{~cm}$. After 360 min with a nearly linear slow increase, the soil moisture tented to be constant at a value of $22.4 \%$. The wetting front moved

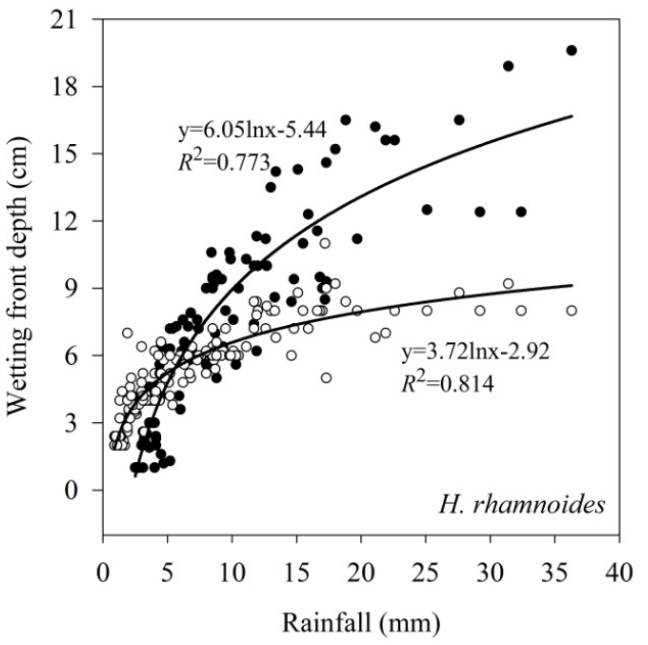

Fig. 6. Relationship between rainfall depths and wetting front depths in the soil around the stem and outside the canopy from May to September of 2009-2013 for C. korshinskii and H. rhamnoides.

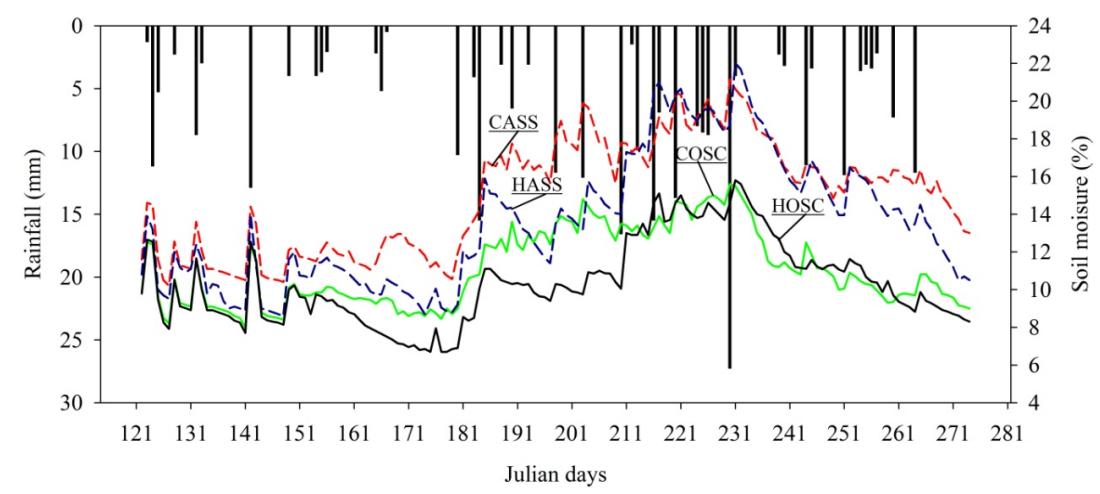

Fig. 7. Soil moisture distribution in the soil profile around the shrub stem and outside the shrub canopy from May to September of 2012 for C. korshinskii and H. rhamnoides. Red line, C. korshinskii around the shrub stem (CASS); green line, C. korshinskii outside the shrub canopy (COSC); blue line, H. rhamnoides around the shrub stem (HASS); black line, H. rhamnoides outside the shrub canopy (HOSC); the bar, rainfall. 


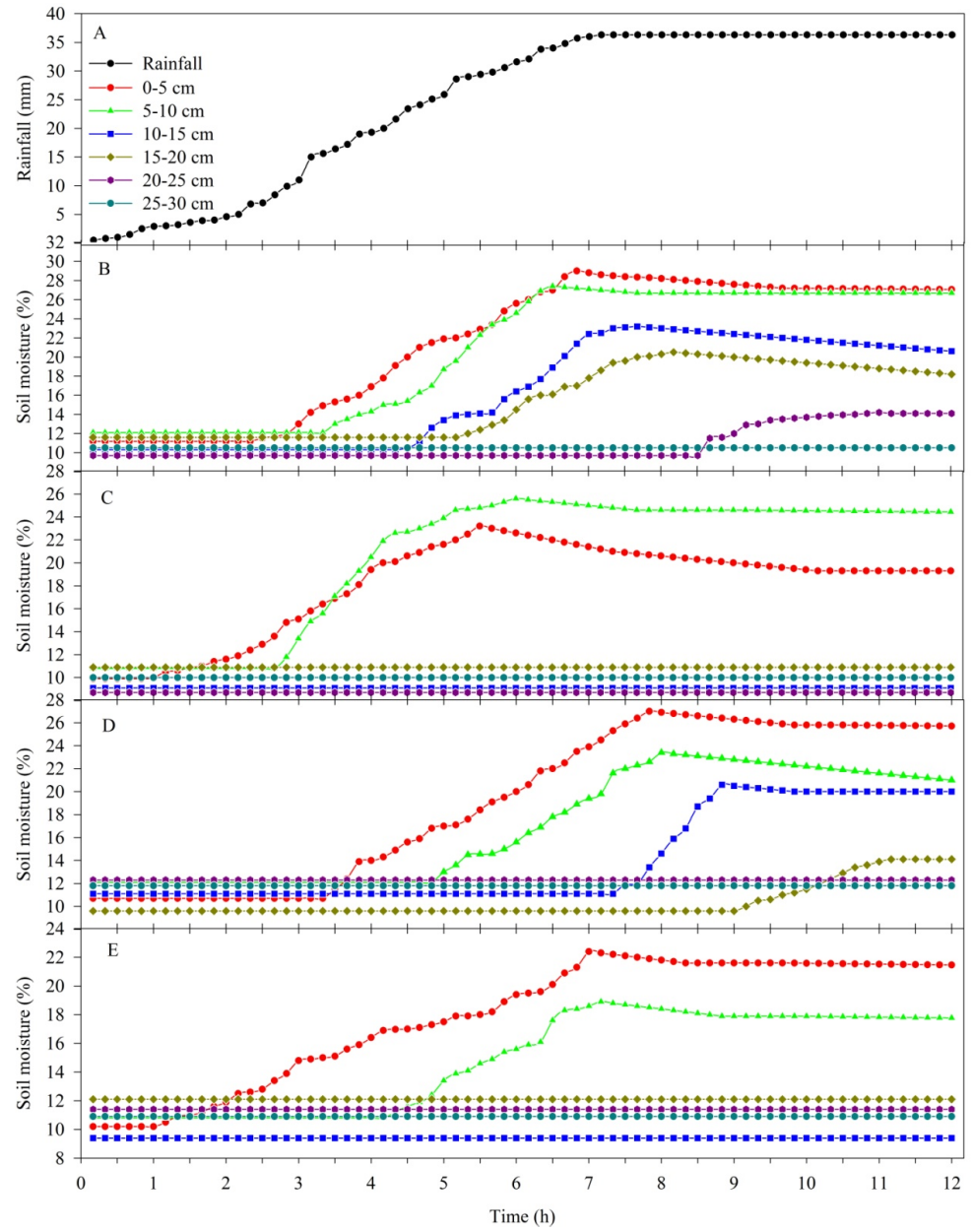

Fig. 8. The wetting front infiltration processes in the area around the shrub stem and that outside the shrub canopy for $C$. korshinskii and H. rhamnoides. $\mathrm{A}$, rainfall processes; $\mathrm{B}$ and $\mathrm{C}$, the area around the shrub stem and that outside the shrub canopy for C. korshinskii; D and E, the area around the shrub stem and that outside the shrub canopy for $H$. rhamnoides.

from $5 \mathrm{~cm}$ to $10 \mathrm{~cm}$, which took $190 \mathrm{~min}$. At this position, the soil moisture at a depth of $15 \mathrm{~cm}$ until $14 \mathrm{~h}$ later. The water infiltrated to a depth of $50 \mathrm{~cm}$ approximately 4 days later. The soil moisture below $50 \mathrm{~cm}$ depth did not change (Fig. 8E).

\section{The relationship between rainfall and cumulative infiltration}

The cumulative infiltration $I(\mathrm{~mm})$ increased with increasing rainfall depth $P(\mathrm{~mm})$, followed significantly positive linear relationships in the area around shrub stem and outside the canopy for $C$. korshinskii and $H$. rhamnoides (Fig. 9). They can be presented mathematically as:

$$
\begin{array}{ll}
I_{\text {around stem of } C \text {. korshinskii }}=0.58 P-1.31, & R^{2}=0.92 \\
I_{\text {outside canopy of } C \text {. korshinskii }}=0.36 P-1.16, & R^{2}=0.78 \\
I_{\text {around stem of } H . \text { rhamnoides }}=0.48 P-1.43, & R^{2}=0.87 \\
I_{\text {outside canopy of } H . \text { rhamnoides }}=0.47 P-1.80, & R^{2}=0.88
\end{array}
$$

\section{Stemflow properties}

The cumulative stemflow amounts were 76.9 and $31.5 \mathrm{~mm}$ during the experimental period (from May to September of 2009-2013) for $C$. korshinskii and H. rhamnoides. However, expressed as percentages of gross rainfall, the mean stemflow percentage of C. korshinskii was $6.9 \%$, which was 2.5 times greater than $H$. rhamnoides. All these results indicated that $C$. korshinskii had stronger ability of stemflow generation than $H$. rhamnoides.

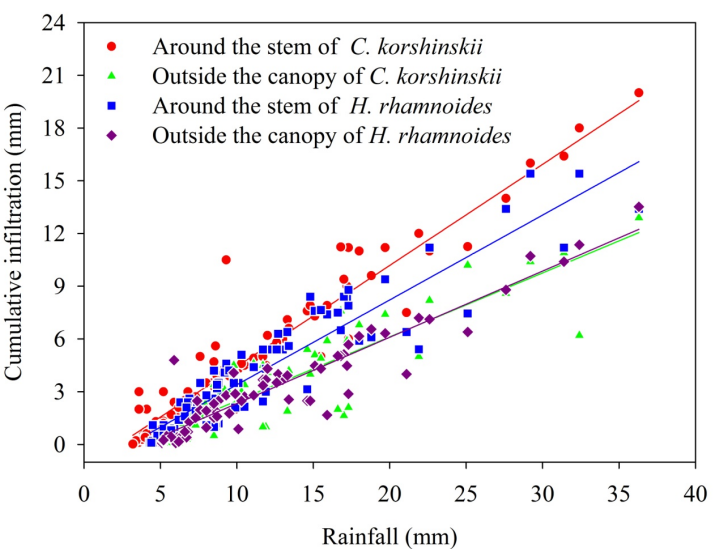

Fig. 9. The relationship between precipitation and cumulative infiltration.

Rainfall of at least 0.5 and $2.5 \mathrm{~mm}$ was necessary to initiate stemflow according to the linear regression based on the five years experiment (Fig. 3). Almost all the previous studies obtained the rainfall threshold according to one year experiment (Carlyle-Moses, 2004; Li et al., 2008). This threshold is consistent with the values reported by previous studies about shrubs in arid and semiarid regions (Enright, 1987; Martinez-Meza and Whitford, 1996; Li et al., 2008; Wang et al., 2013). The studies of Wang et al. (2011b) and Zhang et al. (2013) were based on one year experiment data in the Tengger Desert which reported that an antecedent precipitation of 2.2 and $1.3 \mathrm{~mm}$ was necessary for stemflow initiation for $C$. korshinskii. Our result $(0.5 \mathrm{~mm})$ was less than the above studies, this may be due to the different amount of data, different rainfall characteristics and environmental conditions. C. korshinskii had lower rainfall threshold and stronger ability to generate stemflow than $H$. rhamnoides, which may be due to the smooth bark associated with $C$. korshinskii. $C$. korshinskii has small strip- or linear-shaped leaves, and the twigs, branches and leaves are covered by wax layers, which result in a smooth "funnel" to generate stemflow. Our previous study found that $H$. rhamnoides has the greater water storage capacity than C. korshinskii, which is associated with smooth bark had been shown to be considerably less than that of rough bark (Jian et al., 2013). By contrast, $H$. rhamnoides has numerous branches with thick dense leaves, and there are many diagonal cracks in the surface of branches. The relative rough bark and thick leaves in H. rhamnoides than C. korshinskii may store more rain water, therefore leading to greater water storage capacity and lower efficiency of stemflow production.

Stemflow increased with increasing rainfall depth, followed a positive linear function, which has been reported by other studies (Carlyle-Moses, 2004; Carlyle-Moses and Price, 2006; Martinez-Meza and Whitford, 1996; Wang et al., 2013). The weak correlations were found between stemflow and mean rainfall intensity, maximum rain intensity in 10 minutes, this may be because of most of the initial rainfall was stored by the canopy during rainfall events with low intensity. With the increase of rainfall input, the shrub canopy becomes saturated gradually 
and thus the area contributing to stemflow increased until a rainfall threshold was reached that saturated the whole canopy (Llorens and Gallart, 2000).

Multiple Stepwise linear regression equation of stemflow with the canopy structures indicated that projected area and branch angle governed the stemflow production for C. korshinskii and $H$. rhamnoides (Eqs. (3)-(4)). The inclination of the main branches was various in all the shrubs, with a relatively wide range of insertion angles $\left(46-64^{\circ}\right.$, C. korshinskii; $48-70^{\circ}$, H. rhamnoides; Table 1). It is known that stemflow is enhanced when the plant structure is cone or funnel shaped, since vertically orientated branches with insertion angles greater than $45^{\circ}$ measured above the horizontal promote water flow towards the trunk (Levia and Germer, 2015; Pypker et al., 2005). A funnel shape is indeed a prerequisite for high stemflow production but is not sufficient on its own because the position of the leaves and their orientation and size also affect stemflow (Nanko et al., 2006; Park and Cameron, 2008).

The funnelling ratio differed greatly for different rainfall events, depending on the rainfall depth and rainfall intensity. There were rainfall depths thresholds of 17 and $10.0 \mathrm{~mm}$ for $C$. korshinskii and $H$. rhamnoides. When rainfall was less than the threshold, the funnelling ratio increased with increasing rainfall depth and had a stable trend when the rainfall threshold was reached. Funnelling ratios have been found to be greater than 10 , and in some rainfall events, far greater than 10 . Our studies found that there can be ten or even a hundred times the rainfall amount that may be transported into the root area by stemflow as compared to the area outside the shrub canopy. The excess water effectively supplied the moisture of the upper soil layer, and then formed a greater water potential gradient among the different soil layers. Therefore, the water can infiltrate to the deeper soil becomes higher around shrub stems. Also, stemflow water of shrubs in semiarid regions may be distributed to a deep soil layer by preferential flow along root channels (MartinezMeza and Whitford, 1996; Wang et al., 2011b).

\section{Soil water}

The soil moisture profiles display different vertical structures among the area around stem and outside the canopy for $C$. korshinskii and $H$. rhamnoides. The infiltration process is controlled by several biophysical factors, including ground cover, soil type, hydraulic properties, rainfall characteristics (such as rainfall amount, intensity and duration), meteorological conditions, seasonality and shrub canopy structure and soil surface features (Laio et al., 2001; Zhang et al., 2013). The wetting fronts of the area outside the canopy reached a depth of $5 \mathrm{~cm}$ more quickly than that around stem because most of the initial rainfall was intercepted by the canopy without producing stemflow for C. korshinskii and H. rhamnoides. With increasing soil depth, the advance of the wetting front moved quicker in the area around stem than that outside the canopy, this may be due to the existence of the preferential flow and roots (Fig. 8). The wetting front advanced to depths of 120 and $100 \mathrm{~cm}$ at the area around stem and to depths of $50 \mathrm{~cm}$ at the area outside the canopy for $C$. korshinskii and H. rhamnoides suggested that more rain water can be conserved into the deeper soil layers through shrub stemflow. Wang et al. (2011a) also found that stemflow can double the effective rainfall in terms of the soil moisture replenishment in the root zone below $5 \mathrm{~cm}$ depth. Our previous study found that $C$. korshinskii had more developed root systems than $H$. rhamnoides, which resulted in more soil macropore and preferential flow (Jian et al., 2014a). Stemflow water can effectively supply the soil profile and increase the cumulative infiltration (Fig. 9). Soil moisture was enhanced in the area outside the shrub canopy, only when rainfall depth is $>$ 4.7 and $5.1 \mathrm{~mm}$, which is an effective rainfall for the area for $C$. korshinskii and H. rhamnoides. While for the area around stem of $C$. korshinskii and H. rhamnoides, the corresponding threshold values are 3.2 and $4.3 \mathrm{~mm}$ (Fig. 9). Consequently, stemflow strengthened the effective rainfall in terms of the soil moisture enhancement in the root zone. Also, Wang et al. (2011b) found that the soil profile can be effectively replenished by stemflow water and increase the cumulative infiltration for medium and large rainfall. The corresponding threshold value is about $4 \mathrm{~mm}$ which replenish the soil moisture at the profile deeper than 5 $\mathrm{cm}$ for the stem basal area of C. korshinskii, comparing it to the rainfall of $3.5 \mathrm{~mm}$ that limited the soil moisture increment within the upper layer of $5 \mathrm{~cm}$. Zheng et al. (2015) and Wei and $\mathrm{Wu}$ (2013) reported that the litter intercepting rate averaged $14.2 \%$ in C. korshinskii and $20.8 \%$ in H. rhamnoides stands, respectively in west of Liaoning Province, China. However, there were few organic litter of leaves and sparse grasses were observed beneath the shrub canopies in the current study, so we ignored the water intercepted by them. Also, in our previous study (Jian et al., 2014b), we found that there were little differences in soil evaporation between the area around the shrub stem and outside the shrub canopy, thus, we eliminated the disturbance of shading beneath shrubs to soil moisture.

\section{CONCLUSIONS}

A better understanding of the stemflow variability and its contribution to soil moisture is essential in the re-vegetation efforts of inhabited semiarid regions. Funnelling ratios all are larger than 1 for $C$. korshinskii and H. rhamnoides, indicating that branches and stem were fully contributing to stemflow generation. Relatively larger values of funnelling ratios for $C$. korshinskii suggests that $C$. korshinskii was most effective for stemflow production, which results in more water that can be conserved into the deep layers of the soil. Deeper wetting fronts and higher water contents in the root area around the two shrubs than that in the area outside the shrub canopy in the study suggests that shrub stemflow can be an available moisture source for plant growth under arid conditions and that water redistribution by shrubs can be considered an essential property of the plants that contributes to the stability of shrub communities in harsh environments.

Because of the structural properties of the shrubs and the surface characteristics of their leaves provide the potential for deposition and accumulation of dust and dry fall on the leaf surfaces, so stemflow could transport those materials to the soil under the shrub, which could contribute to the development of 'fertile islands' under shrub canopies. Higher values of funnelling ratios for $C$. korshinskii and $H$. rhamnoides imply that stemflow in the two shrubs can also be an available nutrient source for plant growth under semiarid conditions.

Acknowledgements. This project was supported by National Key Research Priorities Program of China (2016YFC0402402); National Natural Science Foundation of China (31700370); National Natural Science Foundation of China (51409116); Startup Research Fund of Zhengzhou University (1512323001); Institution of higher learning key scientific research project, Henan Province (16A570010); China postdoctoral science foundation (2016M602255); Henan province postdoctoral science foundation; National Natural Science Foundation of China (91025015). 


\section{REFERENCES}

Aboal, J. R., Morales, D., Hernandez, M., 1999. The measurement and modelling of the variation of stemflow in a laurel forest in Tenerife, Canary Islands. Journal of Hydrology, 221, 3-4, 161-175.

Carlyle-Moses, D.E., 2004. Throughfall, stemflow and canopy interception loss fluxes in a semi-arid Sierra Madre Oriental matorral community. Journal of Arid Environments, 58, 181-202.

Carlyle-Moses, D.E., Price, A.G., 2006. Growing-season stemflow production within a deciduous forest of southern Ontario. Hydrological Processes, 20, 3651-3663.

Diskin, M.H., 1970. Definition and uses of the linear regression model. Water Resources Research, 6, 1668-1673.

Dunkerley, D., 2008. Identifying individual rain events from pluviograph records: a review with analysis of data from an Australian dry land site. Hydrology Processes, 22, 5024-5036.

Enright, N.J., 1987. Stemflow as a nutrient source for nikau palm (Rhopalostylis sapida) in a New Zealand forest. Australian Journal of Ecology, 12, 17-24.

Herwitz, S.R., 1986. Infiltration-excess caused by stemflow in a cyclone-prone tropical rainforest. Earth Surface Processes and Landforms 11, 401-412.

IUSS Working Group WRB., 2006. World reference base for soil resources 2006. $2^{\text {nd }}$ edition. World Soil Resources Reports No. 203. FAO, Rome.

Jian, S.Q., Zhao, C.Y., Fang, S.M., Yu, K., 2013. Water storage capacity of the canopy dominated by Caragana korshinskii and Hippophae rhamnoides in hilly and gully region on the Loess Plateau of Northwest China. Chinese Journal of Plant Ecology, 37, 1, 45-51. (In Chinese with English abstract.)

Jian, S.Q., Zhao, C.Y., Fang, S.M., Yu, K., 2014a. Distribution of fine root biomass of main planting tree species in Loess Plateau, China. Chinese Journal of Applied Ecology, 25, 7, 1905-1911. (In Chinese with English abstract.)

Jian, S.Q., Zhao, C.Y., Fang, S.M., Yu, K., 2014b. Soil water content and water balance simulation of Caragana korshinskii Kom. in the semiarid Chinese Loess Plateau. Journal of Hydrology and Hydromechanics, 62, 2, 89-96.

Jiao, F., Wen, Z.M., An, S.S., 2011. Changes in soil properties across a chronosequence of vegetation restoration on the Loess Plateau of China. Catena, 86, 110-116.

Kéfi, S., Rietkerk, M., Alados, C., Pueyo, Y., Papanastasis, V., Elaich, A., De Ruiter, P. 2007. Spatial vegetation patterns and imminent desertification in Mediterranean arid ecosystems. Nature, 449, $213-$ 217.

Laio, F., Porporatro, A., Ridolfi, L., Rodriguez-Iturbe, I., 2001. Plants in water-controlled ecosystems: active role in hydrologic processes and response to water stress. Advances in Water Resources, 24, 707-723.

Levia, D.F., Frost, E.E. 2003. A review and evaluation of stemflow literature in the hydrologic and biogeochemical cycles of forested and agricultural ecosystems. Journal of Hydrology, 274, 1-4, 1-29.

Levia, D.F., Germer, S., 2015. A review of stemflow generation dynamics and stemflow-environment interactions in forests and shrublands. Reviews of Geophysics, 53, DOI: 10.1002/2015RG000479.

Li, X.Y., Liu, L.Y., Gao, S.Y., Ma, Y.J., Yang, Z.P., 2008. Stemflow in three shrubs and its effect on soil water enhancement in semiarid loess region of China. Agricultural and Forest Meteorology, 148, $10,1501-1507$.

Llorens, P., Domingo, F., 2007. Rainfall partitioning by vegetation under Mediterranean conditions. A review of studies in Europe. Journal of Hydrology, 335, 37-54.

Llorens, P., Gallart, F., 2000. A simplified method for forest water storage capacity measurement. Journal of Hydrology, 240, 131144.

Martinez-Meza, E., Whitford, W.G., 1996. Stemflow, throughfall and channelization of stemflow by roots in three Chihuahuan desert shrubs. Journal of Arid Environments, 32, 3, 271-287.

Mauchamp, A., Janeau, J.L., 1993. Water funnelling by the crown of Flourensia cernua, a Chihuahuan Desert shrub. Journal of Arid Environments, 25, 299-306.
Moran, M.S., Scott, R.L., Keefer, T.O., Emmerich, W.E., Hernandez, M., Nearing, G.S., Paige, G.B., Cosh, M.H., O’Neill, P.E., 2009. Partitioning evapotranspiration in semiarid grassland and shrubland ecosystems using time series of soil surface temperature. Agricultural and Forest Meteorology, 149, 59-72.

Nanko, K., Hotta, N., Suzuki, M., 2006. Evaluating the influence of canopy species and meteorological factors on throughfall drop size distribution. Journal of Hydrology, 329, 422-431.

Návar, J., Bryan, R.B., 1990. Interception loss and rainfall redistribution by three semi-arid growing shrubs in northeastern Mexico. Journal of Hydrology, 115, 51-63.

Noy-Meir, I. 1973. Desert ecosystems: environment and producers. Annual Review of Ecology and Systematics, 4, 25-51.

Nulsen, R.A., Bligh, K.J., Baxter, I.N.E.J.S., Imrie, D.H., 1986. The fate of rainfall in a mallee and heath vegetated catchment in southern Western Australia. Australian Journal of Ecology, 11, 361-371.

Park, A., Cameron, J.L., 2008. The influence of canopy traits on throughfall and stemflow in five tropical trees growing in a Panamanian plantation. Forest Ecology and Management, 255, 19151925.

Pypker, T.G., Bond, B.J., Link, T.E., Marks, D., Unsworth, M.H., 2005. The importance of canopy structure in controlling the interception loss: examples from a young and old-growth Douglas-fir forests. Agricultural and Forest Meteorology, 130, 113-129.

Tang, C.Y., 1992. A research on the effects of artificial masson pinus forest on rainfall partitioning in subtropical area. Acta Geographica Sinica, 47, 6, 545-551. (In Chinese with English abstract.)

Tromble, J.M., 1987. Water interception by two arid land shrubs. Journal of Arid Environments, 15, 65-70.

Voigt, G.K. 1960. Distribution of rainfall under forest stands. Forest Science, 6, 1, 2-10.

Wang, X.P., Li, X.R., Zhang, J.G., Zhang, Z.S., Berndtsson, R. 2005. Measurement of rainfall interception by xerophytic shrubs in revegetated sand dunes. Hydrological Sciences Journal 50: 897-910.

Wang, X.P., Wang, Z.N., Berndtsson, R., Zhang, Y.F., Pan, Y.X., 2011a. Desert shrub stemflow and its significance in soil moisture replenishment. Hydrology and Earth System Sciences, 15, 561-567.

Wang, X.P., Zhang Y.F., Wang, Z.N., Pan, Y.X., Hu, R., Li, X.J., Zhang, H., 2013. Influence of shrub canopy morphology and rainfall characteristics on stemflow within a revegetated sand dune in the Tengger Desert, NW China. Hydrological Processes, 27, 10, 1501-1509.

Wang, Y.Q., Shao, M.A., Shao, H.B., 2010. A preliminary investigation of the dynamic characteristics of dried soil layers on the Loess Plateau of China. Journal of Hydrology, 381, 1-2, 9-17.

Wang, Y.Q., Shao, M.A., Zhu, Y.J., Liu, Z.P., 2011b. Impacts of land use and plant characteristics on dried soil layers in different climatic regions on the Loess Plateau of China. Agricultural and Forest Meteorology, 151, 437-448.

Wei, T.X., Zhu, J.Z., Zhang, J.J., Bi, H.X., Zhu, Q.K., 2007. Protective forest system at small watershed in the gullied-hilly loess area based on water balance on the Loess Plateau. Research Soil Water Conservation 14, 179-183. (In Chinese with English abstract.)

Wei, Y.L., Wu, Y.Z., 2013. Study on interception characteristics of different plants. Journal of Soil and Water Conservation, 29, 3, 4653. (In Chinese with English abstract.)

Zhang, G.H., Tang, M.K., Zhang, X.C., 2009. Temporal variation in soil detachment under different land uses in the Loess Plateau of China. Earth Surface Processes and Landforms, 34, 1302-1309.

Zhang, Y.F., Wang, X.P., Hu, R., Pan, Y.X., Zhang, H., 2013. Stemflow in two xerophytic shrubs and its significance to soil water and nutrient enrichment. Ecological Research, 28, 567-579.

Zheng, Y.Y, Xu, X. H., Zhang, Y., Ou, Y., Yan, B.X., Wang, P.J., Cui, H., F., Cui B., 2015. Characteristics of precipitation interception in soil and water conservation forests of the Northeast black soil areas of China. Acta Prataculturae Sinica, 24, 6, 16-24. (In Chinese with English abstract.)

Received 12 June 2017 Accepted 11 September 2017 